\title{
USO DE AREIA GROSSA E MANTA DE POLIÉSTER COMO MATERIAIS-ENVELOPE NUM SISTEMA DE DRENAGEM ${ }^{1}$
}

\author{
Eugênio Ferreira Coelho ${ }^{2}$, Francisco das Chagas Oliveira ${ }^{3}$, Carlos José Araújo Nascimento ${ }^{4}$, \\ Lúcio Flavo Vasconcelos Lopes $^{5}$ \& Eugênio Celso Emérito Araújo ${ }^{5}$
}

\begin{abstract}
RESUMO
Este trabalho foi conduzido num sistema de drenagem em área da empresa Mangal, cultivada com manga variedade Tommy Atkins, na zona rural do município de Teresina, PI, durante os períodos chuvosos de 1997 e 1998. Foram avaliados os efeitos de dois materiais-envelope, areia grossa e manta de poliéster, na eficiência de um sistema de drenagem com linhas de drenos de $120 \mathrm{~m}$ de comprimento, $0,10 \mathrm{~m}$ de diâmetro e espaçamento de $35 \mathrm{~m}$; por outro lado, a avaliação teve, como base, a profundidade do lençol freático durante o período chuvoso, a taxa de rebaixamento do lençol freático e a capacidade de escoamento dos drenos. O monitoramento do lençol freático na área foi realizado em quatro baterias de poços de observação instalados em uma linha ortogonal na direção dos drenos, enquanto a determinação da vazão na saída dos drenos se deu por meio de hidrômetros. As maiores diferenças entre os parâmetros usados para medir a eficiência dos dois materiais-envelope foram detectadas no ano de 1997, quando houve maior elevação do lençol freático conseqüente de um regime pluviométrico mais intenso. O uso de areia grossa como material-envelope resultou em maior eficiência dos drenos, quando comparado com manta de poliéster.
\end{abstract}

Palavras-chave: drenagem, filtro, lençol freático

\section{USE OF COARSE SAND AND POLYESTER AS ENVELOPE MATERIAL IN A DRAINAGE SYSTEM}

\begin{abstract}
The study was carried out in an area of the Mangal Company located in the agricultural zone of Teresina-PI, with Tommy Atkins mango cultivated under a drainage system during the rainy seasons of 1997 and 1998. The effect of two envelope materials (coarse sand and polyester) on the drainage efficiency was evaluated in drains $120 \mathrm{~m}$ long, $0.10 \mathrm{~m}$ diameter and $35 \mathrm{~m}$ apart. The parameters for evaluation were: water table depth, rate of water table drawdown and discharge of water from the drains. The water table monitoring was accomplished by four groups of observation wells installed in a line perpendicular to the direction of the drains. Drain discharge was measured by hydrometers. Results showed that higher differences between parameters used to evaluate the envelope material performance were detected during 1997. Higher elevations of water table as a consequence of more intense precipitation were noticed in this year. The use of coarse sand as envelope material resulted in higher drainage efficiency when compared to polyester material.
\end{abstract}

Key words: drainage, filter, water table

\footnotetext{
${ }^{1}$ Trabalho financiado pelo CNPq

${ }^{2}$ Pesquisador, Embrapa Mandioca e Fruticultura, Rua EMBRAPA S/N, CP 07, Cruz das Almas, BA, CEP 44380 - 000 , E-mail: ecoelho@cnpmf.embrapa.br

${ }^{3}$ Bolsista CNPq, Embrapa Meio-Norte, Av. Duque de Caxias 5650, B. Buenos Aires, Teresina, PI,

${ }^{4}$ Eng. Agrônomo, MANGAL, Rodovia PI 130, km 35, Teresina, PI, CEP 64000

${ }_{5}^{5}$ Pesquisador, Embrapa Meio-Norte, E-mail: 65006-240lucio@cpamn.embrapa.br
} 


\section{INTRODUÇÃO}

Materiais-envelope (Willardson, 1974) ou filtros (Pizarro, 1978; Cruciani, 1980; Eggelsmann, 1982) são essenciais para o aumento da eficiência e durabilidade de um sistema de drenagem em qualquer tipo de solo, especialmente em solos de baixa estabilidade e com significativo teor de silte e areia, com diâmetro médio entre 0,05 e 1,0 mm, entre os quais os de textura franco-arenosa, areia franca e franco-siltosa, que são os mais susceptíveis a entupimentos nos drenos (Eggelsmann, 1982).

Diversos tipos de materiais podem ser usados como envelope ou filtro: areia, cascalho, palha de arroz, fibra de coco e fibra de madeira, além de fibra de vidro, mistura de acrílico e celulose e outros materiais sintéticos, como nylon, fibras de poliéster, poliuretano e polipropileno (Eggelsmann, 1982). Diversos desses materiais-envelope foram avaliados na Holanda sob as condições mais comuns de solo e, exceto pela palha de cereais, os outros apresentaram-se adequados como materiais-envelope, dentro de condições determinadas (Van Someren, 1972). A colocação desses materiais ao redor dos tubos de drenos não necessita envolver todo o contorno do tubo de drenagem, havendo uma redução de $10 \%$ na eficiência relativa, com a colocação dos mesmos envolvendo apenas a parte de baixo do tubo (Dieleman \& Trafford, 1976).

Dentre os materiais à base de fibras de poliéster, Cruciani (1982) cita a manta de poliéster Bidim, como opção para materiais-envelope, com permeabilidade de $360 \mathrm{~cm} \mathrm{~h}^{-1}$ para água limpa e $36 \mathrm{~cm} \mathrm{~h}^{-1}$ para água com argila em suspensão. As mantas de poliéster apresentam, como filtro, espessura de 0,5 $\mathrm{cm}, 1,38 \mathrm{~g} \mathrm{~cm}^{-3}$ de densidade e $90 \%$ de porosidade (Eggelsmann, 1982).

Os elevados custos de implantação dos sistemas de drenagem normalmente levam o produtor a procurar alternativas de materiais de mais fácil aquisição e menor preço, sem perder a eficiência e funcionalidade. A eficiência e a durabilidade do sistema de drenagem constituem os parâmetros principais de avaliação de um material-envelope.

A necessidade de uso de envelopes está condicionada principalmente à estabilidade do solo que, de forma indireta, está relacionada à presença de silte (Eggelsmann, 1982). Broughton et al. (1982) não verificaram diferença significativa entre uso de cascalho e materiais sintéticos, como envelopes.

No uso de envelopes ou filtros, deve-se considerar os precipitados de óxido de ferro, conseqüentes da oxidação do ferro reduzido e diluído na água que escoa para os drenos e que aí, em contato com o oxigênio, oxida-se, formando um material avermelhado e gelatinoso que pode entupir o material filtrante ou envelope, inviabilizando-o. Materiais orgânicos são mais eficientes no caso desses precipitados que materiais sintéticos (Eggelsmann, 1982) em que o material, à base de óxido de ferro, bloqueia os espaços porosos do envelope, aumentando a resistência hidráulica e reduzindo a eficiência de drenagem.

Este trabalho teve por objetivo verificar o comportamento de dois materiais envelopes (areia grossa e manta de poliéster Bidim) num sistema de drenagem dimensionado para uma área com a cultura da manga.

\section{MATERIAL E MÉTODOS}

O experimento foi conduzido numa área de 20 ha da empresa agrícola Mangal, situada no km 35 da Rodovia Teresina - Palmeirais, PI, no período 1997-1998. O solo da área experimental é classificado, de modo geral, como de textura franco-arenosa, cujas características físico-hídricas são apresentadas na Tabela 1 .

Um sistema de drenagem foi instalado na área em 1996, constituído de drenos tubulares subterrâneos de $120 \mathrm{~m}$ de comprimento, espaçados de $35 \mathrm{~m}$, de tubos de PVC perfurados e corrugados de $75 \mathrm{~mm}$ de diâmetro, instalados a $1,5 \mathrm{~m}$ de profundidade.

Durante a instalação do sistema de drenagem foi utilizada, na metade da área, como envelope, areia grossa e, na outra metade, a manta de poliéster. A areia grossa foi usada mantendo-se uma espessura de $0,1 \mathrm{~m}$ em torno do tubo de drenagem (Willardson, 1974).

Entre dois pares de drenos com areia grossa como envoltório e entre dois pares de drenos com manta de poliéster, também como envoltório, selecionados ao acaso, foram instaladas baterias de poços de observação, para monitoramento do lençol freático. Os poços foram instalados na profundidade de $1,0 \mathrm{~m}$ e nas distâncias perpendiculares a direção dos drenos de $0,0,5 ; 1,5 ; 2,5 ; 4,5$ e $17,5 \mathrm{~m}$, conforme Millar (1978).

A freqüência de leitura nos poços de observação foi adotada conforme o regime pluviométrico local, isto é, maior freqüência de leituras (um dia) em períodos de chuvas contínuas e menor freqüência (dois ou mais dias) em períodos de chuvas esporádicas; mediu-se, também, o escoamento de água drenada na área, por meio de hidrômetros instalados na saída dos drenos e a mesma frequiência das leituras dos poços de observação. Para cálculo da lâmina d'água drenada equivalente à área de contribuição de um dreno, foi usada a razão diária entre a vazão na saída do dreno e a sua área de abrangência.

Os dados foram coletados apenas durante o período chuvoso da região (dezembro a maio) uma vez que as precipitações fora deste período não são suficientes para causar excesso de água nem deficiência de aeração no solo, pela elevação do lençol freático da área.

Tabela 1. Características físico-hídricas do solo da área experimental

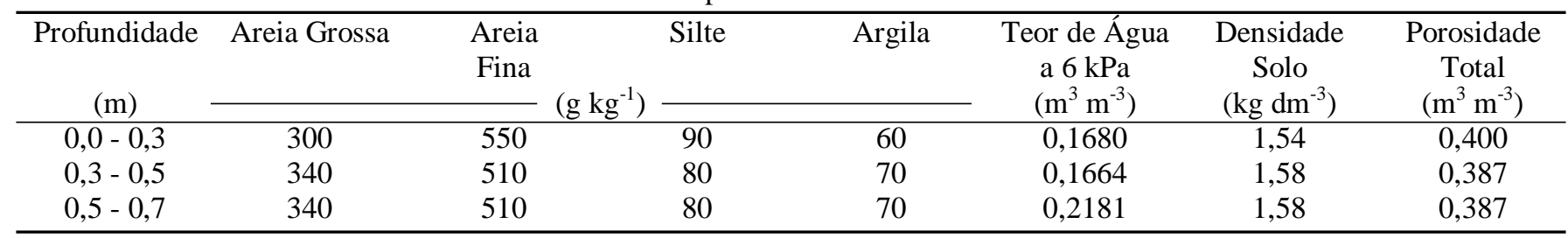




\section{RESULTADOS E DISCUSSÃO}

Os regimes pluviométricos referentes aos períodos chuvosos entre janeiro e junho de 1997 e entre janeiro e março de 1998, são mostrados na Figura 1. No ano de 98, as precipitações se concentraram no período janeiro-março, sendo que as esporádicas subsequientes não foram significativas em termos de elevação do lençol freático da área.
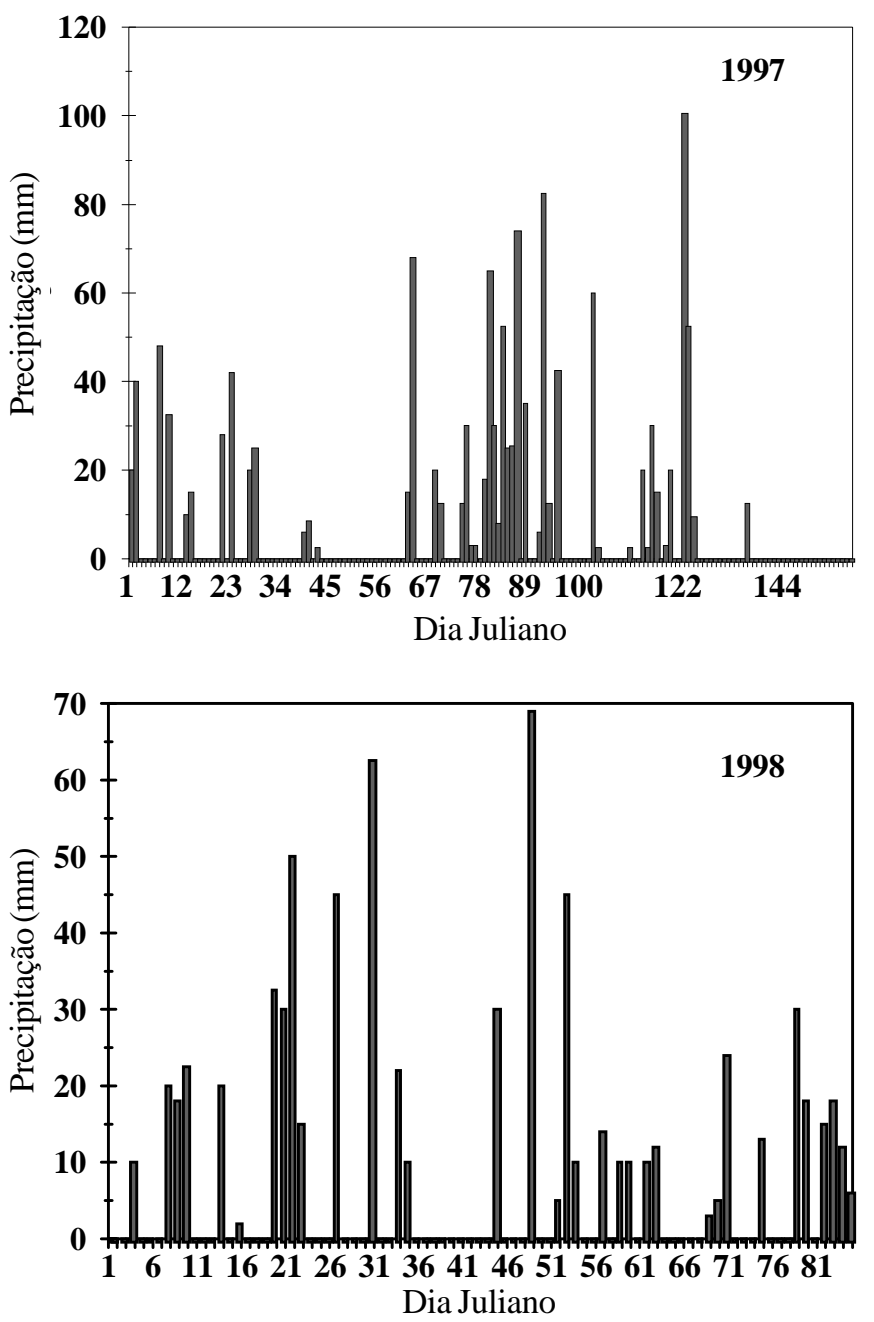

Figura 1. Regime pluviométrico referente aos períodos chuvosos de 1997 e 1998

A Figura 2 expressa a profundidade média do lençol freático a 4,5 $\mathrm{m}$ do dreno com os materiais filtrantes ou envelope (areia e manta de poliéster). A profundidade média do lençol próximo ao dreno com envelope de areia foi superior à profundidade do lençol na mesma posição, próximo ao dreno, com envelope de manta de poliéster, durante o período monitorado nos dois anos.

A diferença entre as profundidades para os dois envelopes, foi em média, de $0,23 \mathrm{~m}$ ao longo do período monitorado em 1997 e de 0,17 m no período monitorado em 1998 . No ano de 1997, em duas das quatro baterias de poços de observação para cada material-envelope, houve estagnação do lençol freático quase na superfície do solo com drenos envoltos por manta de poliéster nos períodos de mais alta pluviosidade, o que não ocorreu no caso dos drenos com areia grossa.
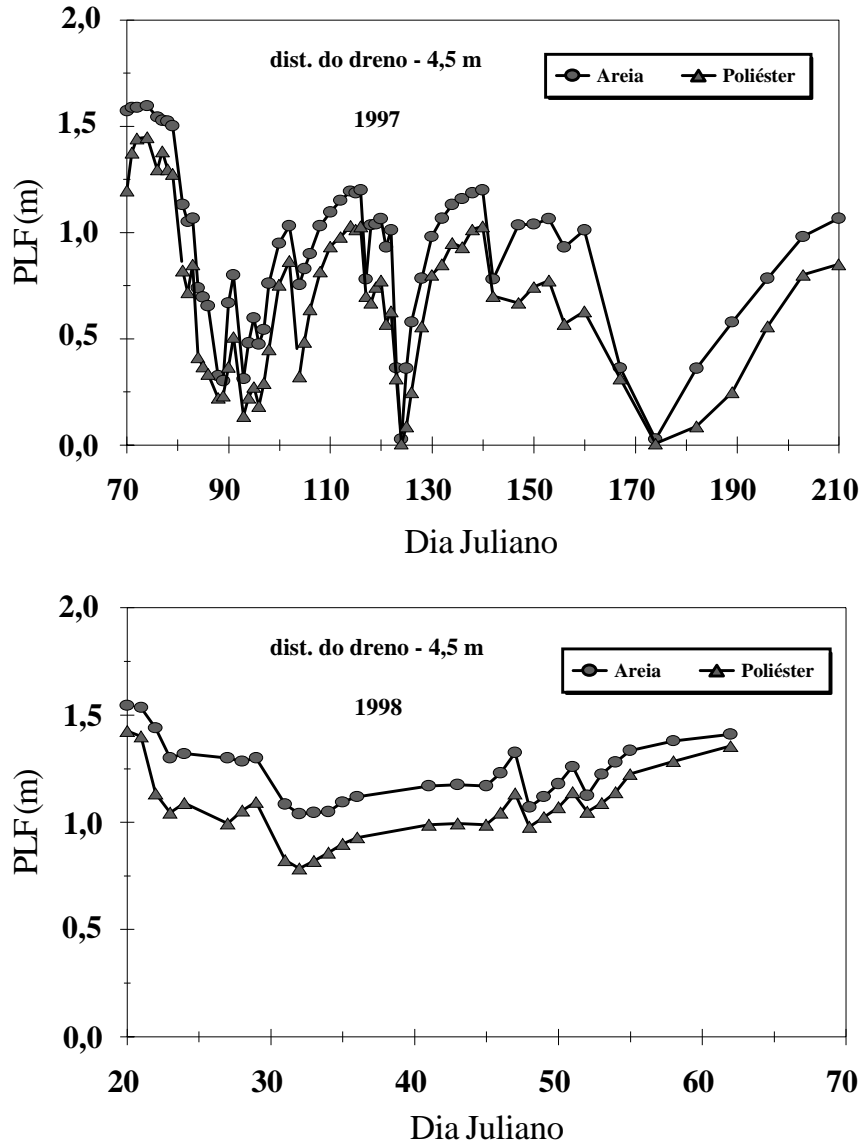

Figura 2. Evolução temporal da profundidade do lençol freático

(PLF) a 4,5 m dos drenos, tendo areia e manta de poliéster como envelope

A Figura 3 apresenta as taxas de rebaixamento do lençol freático em função da profundidade do solo, enquanto as taxas de rebaixamento para os dois materiais-envelope apresentam maiores valores absolutos a menores profundidades do solo, como era esperado (Coelho et al., 1985) dado os maiores gradientes de potenciais com o lençol nessas profundidades. Nessas profundidades, no ano de 1997 as taxas de rebaixamento do lençol freático entre drenos com envelope de areia foram superiores às taxas entre os drenos com envelope de manta de poliéster, sendo que os valores se aproximaram nas profundidades maiores (abaixo de $0,8 \mathrm{~m}$ ) em que as diferenças entre as taxas de rebaixamento do lençol freático para os dois materiais-envelope não deferiram muito em valores absolutos, em geral, abaixo de $0,06 \mathrm{~m} \mathrm{dia}^{-1}$ (Figura 3).

A Figura 4 ilustra o rebaixamento do lençol freático entre os dias julianos 94 a 100, referentes a 1997, e entre os dias julianos 32 a 43 referentes, a 1998, confirmando as taxas de rebaixamento observadas na Figura 3. Observa-se maior diferença entre o comportamento do lençol freático (favorável a areia grossa) referente aos materiais-envelope para o ano de 1997, quando o lençol atingiu profundidades menores no perfil do solo. No ano de 1998, dado às menores precipitações, não houve elevação acentuada do lençol freático, com registro de suas posições apenas a maiores profundidades, em que as diferenças entre as posições do lençol freático foram menores, ora favorecendo um ou outro material-envelope. 

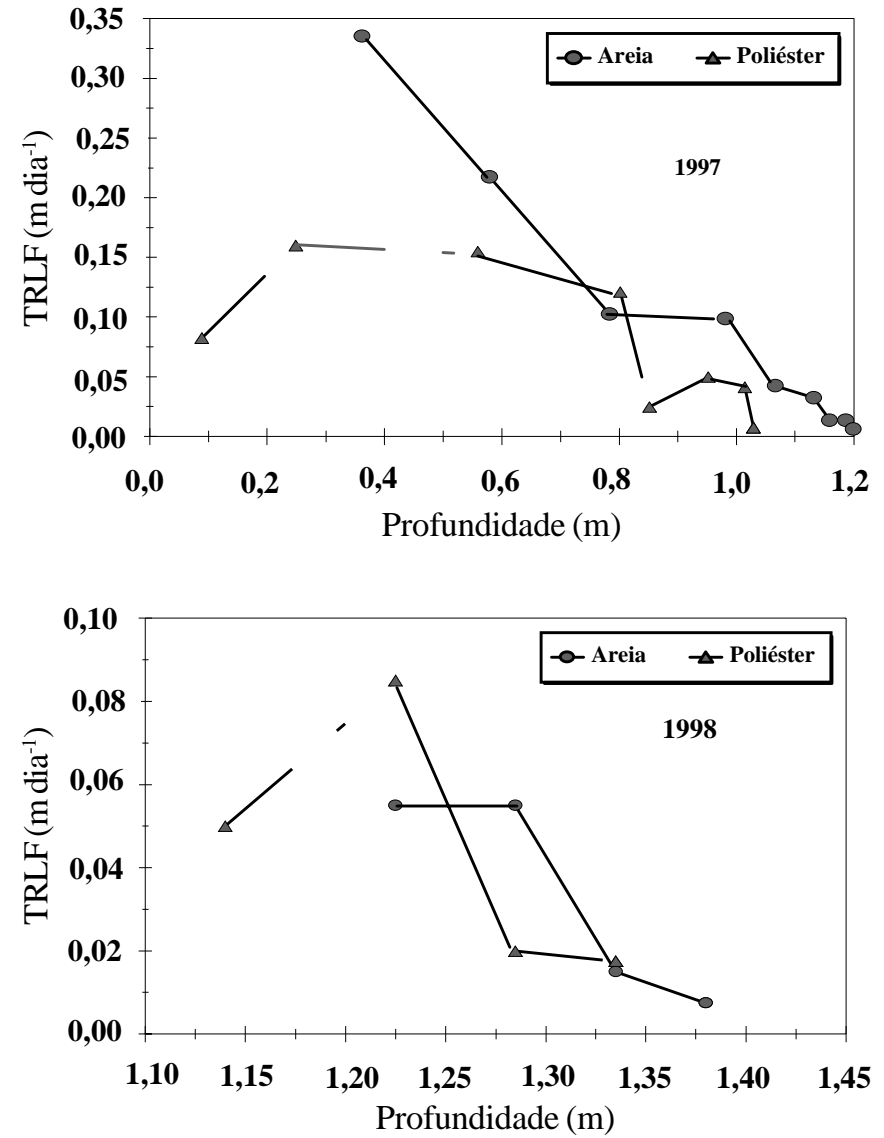

Figura 3. Taxa de rebaixamento do lençol freático (TRLF) relativa aos drenos com envelope de areia grossa e manta de poliéster, após interrupção na precipitação nos períodos chuvosos de 1997 e 1998
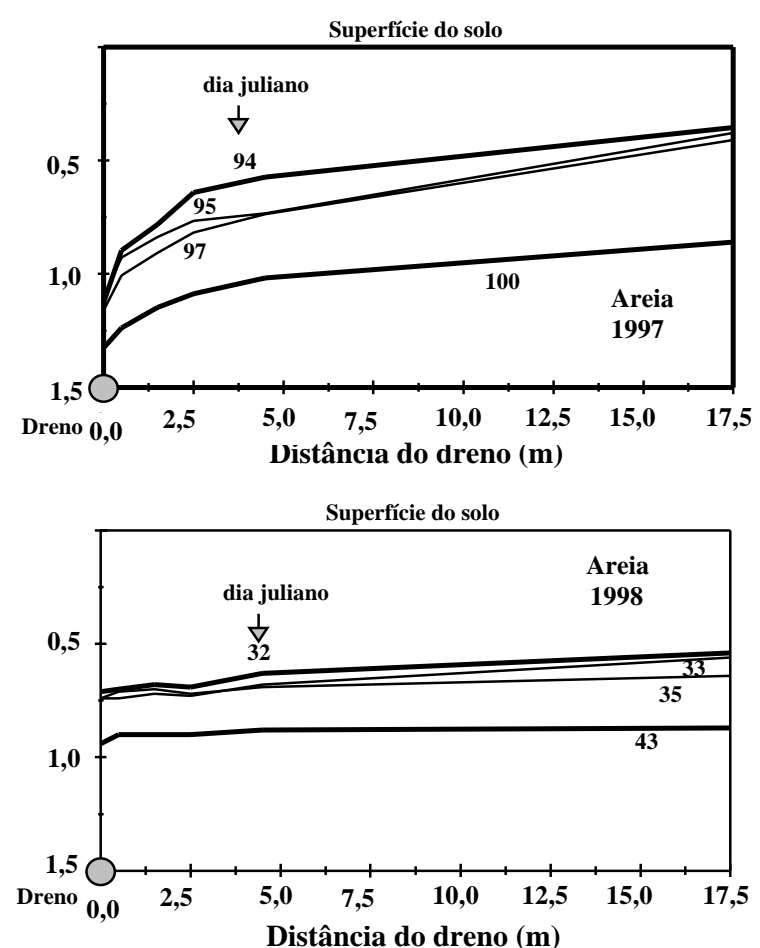

A Figura 5 apresenta as lâminas diárias escoadas nos drenos com envoltórios de areia e manta de poliéster para os anos de 1997 e 1998. Durante o período chuvoso de cada ano, a oscilação da vazão foi função direta da oscilação da precipitação. A Figura 5 mostra que a capacidade máxima de drenagem dos drenos que tiveram areia grossa como materialenvelope, foi de $4,5 \mathrm{~mm} \mathrm{dia}^{-1}$ no período avaliado de 1997 , contra 1,8 $\mathrm{mm} \mathrm{dia}^{-1}$ para os drenos com manta de poliéster e, em 1998, o escoamento máximo observado foi de $1,8 \mathrm{~mm} \mathrm{dia}^{-1}$ para os drenos com areia grossa como material envelope, contra $1,4 \mathrm{~mm} \mathrm{dia}^{-1}$ para os drenos com manta poliéster.

O valor de 4,5 mm dia ${ }^{-1}$ do período avaliado em 1997 dificilmente poderá ser ultrapassado, em razão da ocorrência de uma precipitação de $100 \mathrm{~mm}$, que condicionou esta drenagem. A integração numérica das curvas referentes à Figura 5 permitiu obter-se a lâmina acumulada escoada pelos drenos com diferentes materiais-envelope, num mesmo período observado. Os valores da lâmina acumulada reforçam a superioridade da areia grossa como material envelope mais eficiente que a manta de poliéster, pela diferença de 59,3 mm entre a lâmina acumulada escoada pelos drenos com material filtrante areia grossa e a lâmina acumulada escoada pelos drenos com material filtrante poliéster, durante o período em que se mediu a vazão nos drenos, no ano de 1997. Em 1998, a superioridade da areia grossa, em termos de eficiência de drenagem, pode ser observada, também, por meio dos valores da lâmina acumulada, em que a diferença a favor da areia grossa foi de 14,4 $\mathrm{mm}$ no período observado. Esta diferença, bem menor que a do ano anterior, é devida às menores precipitações ocorridas no período chuvoso de 1998, comparado com o período chuvoso de 1997. Não houve elevação acentuada do lençol freático em 1998, ao contrário de 1997, o que reduziu a lâmina escoada e a diferença entre essas lâminas para os dois materiais drenantes avaliados.
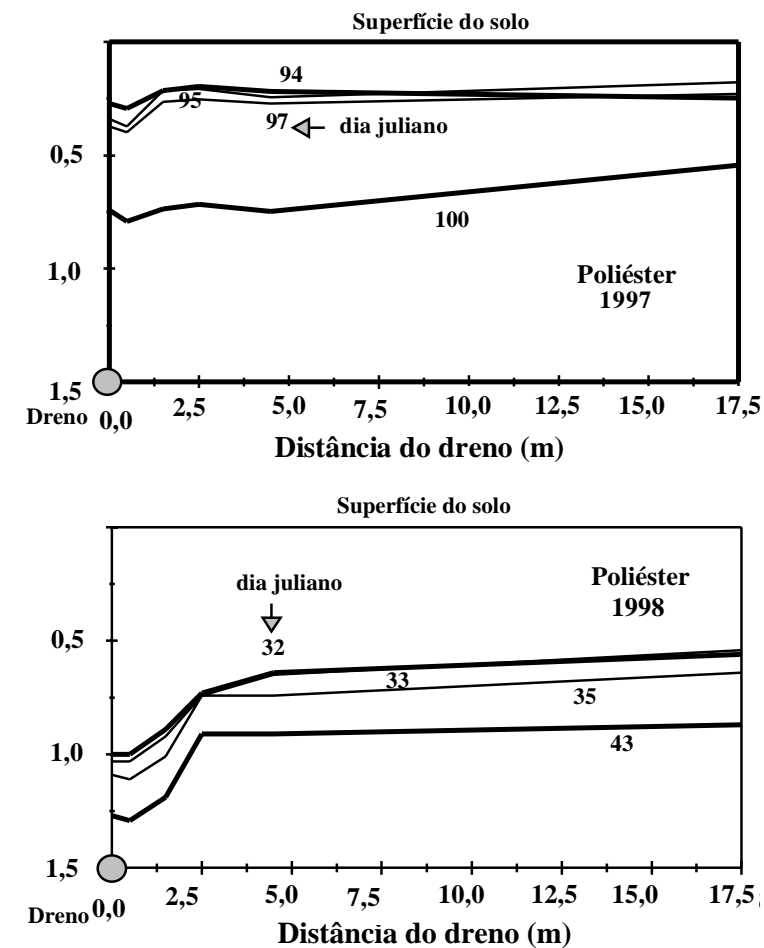

Figura 4. Posição do lençol freático relativa à superfície do solo para drenos com envelope de areia grossa e manta de poliéster, em dois períodos de rebaixamento do lençol freático, em 1997 e 1998 

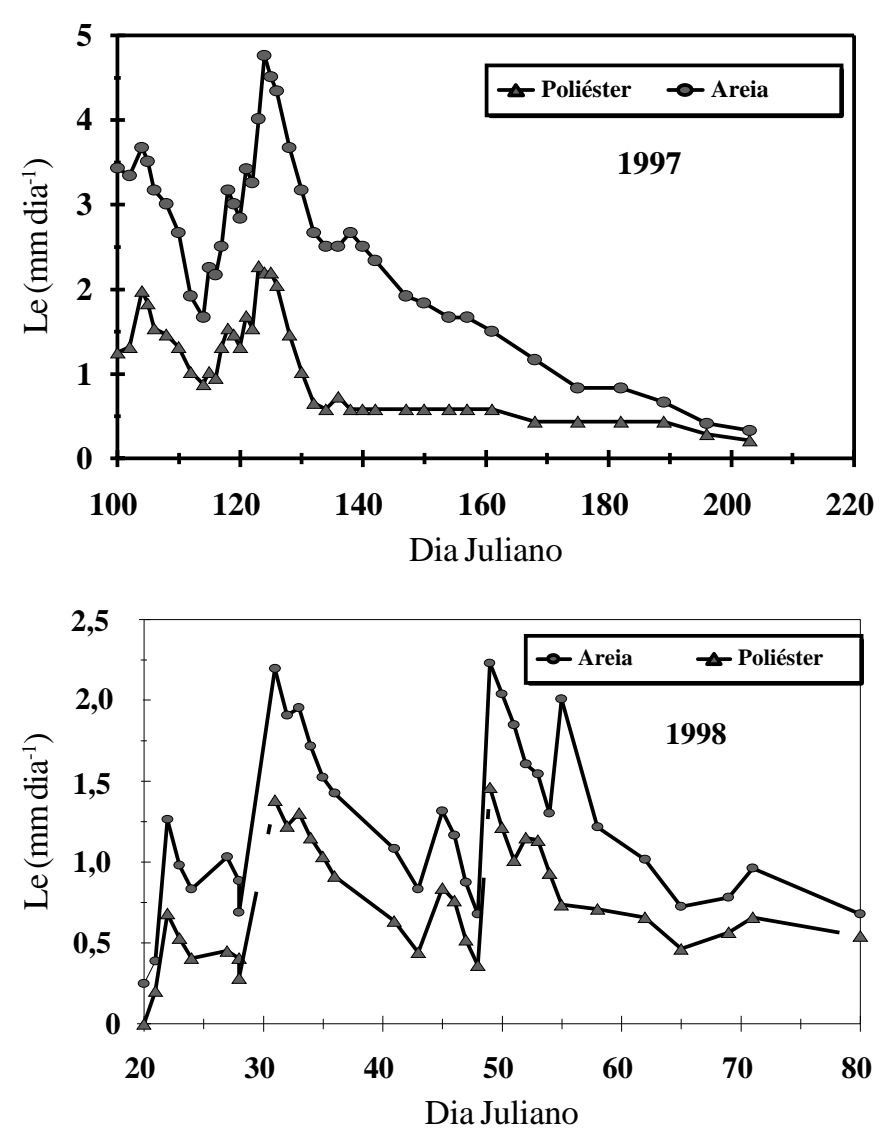

Figura 5. Evolução temporal da lâmina escoada (Le) na saída dos drenos, contendo areia grossa e manta de poliéster como envelope

Dentre as possíveis causas da maior eficiência do material filtrante areia grossa, está o fato de a areia grossa servir como envelope, reduzindo a resistência hidráulica em conseqüência da maior espessura do material filtrante, enquanto a manta de poliéster não condiciona redução na resistência hidráulica em torno do dreno; outro fator de influência nos resultados é a presença de material de ferro oxidado, que fluiu dos drenos em abundância, principalmente naqueles envoltos com areia grossa e que, provavelmente, contribuiu significantemente para a menor eficiência da manta de poliéster.

\section{CONCLUSÕES}

1. As maiores diferenças entre as variáveis usadas para se medir a eficiência dos dois materiais-envelope, foram detectadas quando houve maior elevação do lençol freático conseqüente de um regime pluviométrico mais intenso.

2. A capacidade máxima de escoamento dos drenos com envelope de areia grossa foi de 4,5 $\mathrm{mm} \mathrm{dia}^{-1}$ contra $1,8 \mathrm{~mm} \mathrm{dia}^{-1}$, referente aos drenos envoltos com manta de poliéster, para um regime pluviométrico com precipitações diárias de até $100 \mathrm{~mm}$.

3. O uso de areia grossa como material-envelope resultou em maior eficiência dos drenos, quando comparado com a manta de poliéster.

\section{REFERÊNCIAS BIBLIOGRÁFICAS}

BROUGHTON, R.S.; GAMEDA, S.; GIBSON, W. Field tests of some drain tube envelope materials. In: National Drainage Symposium, 4, Chicago, ASAE, 1982. p.69-78.

COELHO, E.F.; FERREIRA, P.A.; CAIXETA, T.J.; BERNARDO, S.; LOUREIRO, B.T. Eficiência de algumas equações de drenagem no dimensionamento de drenos abertos e cobertos em condições de campo. Ceres, v. 32, p.43-62. 1985.

CRUCIANI, D.E. A drenagem na agricultura. São Paulo: Nobel, 1980.333p.

DIELEMAN, P.J.; TRAFFORD, B.D. Drainage Testing. Rome: FAO, 1976. 172p. Irrigation and Drainage paper $\mathrm{N}^{\circ} 28$

EGGELSMANN, R. Two decades of experience with drainage filters in the Federal Republic of Germany. In: National Drainage Symposium, 4, Chicago, ASAE, 1982. p.115-120.

MILLAR, A. Drenagem de terras agrícolas: Bases agronômicas. São Paulo: McGraw-Hill do Brasil. 1978. 276p.

PIZARRO, F. Drenaje agricola y recuperacion de suelos salinos. Madrid: Agrícola Espanhola, 1978. 525p.

van SOMEREN, C.L. Drainage materials. In: Drainage materials. Rome: FAO. 1972. p.1-25. Irrigation and Drainage paper № 9

WILLARDSON, L.S. Envelope materials. In: van SCHILFGAARDE, J. ed. Drainage for agriculture. Madison: American Society of Agronomy, 1974. p.179-197. Agronomy Monograph, 17 